\title{
Epidemiological Characteristics of New Coronavirus Diseases (COVID-19): Features of Risk Factors and Clinical Features of the Child Population
}

\author{
Kanatzhan Kemelbekov ${ }^{1 \star}$, Elmira Ospanova ${ }^{2}$, Bakhtygul Baimakhanova ${ }^{3}$, Zharylkap Zhumabekov ${ }^{3}$, \\ Klara Zholdas ${ }^{4}$, Zhuldyz Yessentayeva ${ }^{5}$, Akerke Zaidulla ${ }^{6}$
}

\begin{abstract}
${ }^{1} \mathrm{PhD}$, Assistant of the Department of Pediatrics-2, South Kazakhstan Medical Academy, 160000 Shymkent, Al-Farabi-1, KAZAKHSTAN ${ }^{2}$ Associate Professor of the Department of Preventive Medicine, Khoja Akhmet Yassawi International Kazakh-Turkish University, Turkestan, KAZAKHSTAN ${ }^{3}$ Associate Professor of the Department of Pediatrics -1,2, South Kazakhstan Medical Academy, 160000 Shymkent, Al-Farabi-1, KAZAKHSTAN

${ }^{4}$ Senior Lecturer of the Department of Preventive Medicine, Khoja Akhmet Yassawi International Kazakh-Turkish University, Turkestan, KAZAKHSTAN

${ }^{5}$ Teacher of the Department of Preventive Medicine, Khoja Akhmet Yassawi International Kazakh-Turkish University, Turkestan, KAZAKHSTAN

${ }^{6}$ Resident Student of the Department of Pediatrics, South Kazakhstan Medical Academy, 160000 Shymkent, Al-Farabi-1, KAZAKHSTAN

*Corresponding Author: kanat-270184@mail.ru
\end{abstract}

Citation: Kemelbekov K, Ospanova E, Baimakhanova B, Zhumabekov Z, Zholdas K, Yessentayeva Z, Zaidulla A. Epidemiological Characteristics of New Coronavirus Diseases (COVID-19): Features of Risk Factors and Clinical Features of the Child Population. Electron J Gen Med. 2020;17(6):em252. https://doi.org/10.29333/ejgm/8268

\section{ARTICLE INFO}

Received: 1 Apr. 2020

Accepted: 8 May 2020

\begin{abstract}
The article presents features of epidemiology and clinical picture of a new virus - COVID-2019 in Kazakhstan, features of dynamics among the child population. As of April 15, 2020, there are 1,295 cases of COVID-19. In total, the infection was confirmed in 80 children. Among them, one newborn, two children under one year old and this has allowed to limit the spread of this serious disease with the cooperation of all citizens in terms of containment and individual protection measures. Objective: to evaluate the prevalence, clinical and epidemiological features and risk factors of COVID-19 in children of different ages. The design of the study corresponded to the observational analytical one. The COVID-19 pandemic has spread very quickly, so it is children of all ages who should be the focus of special attention, as they play a huge role in the spread of the disease.
\end{abstract}

Keywords: COVID-19, epidemiology, clinical features, child population

\section{INTRODUCTION}

Coronaviruses (Coronaviridae) are a large family of RNAcontaining viruses that can infect humans and certain animals. In humans, coronaviruses can cause a range of disfunctions, from mild forms of acute respiratory infection to severe acute respiratory syndrome (SARS). Currently, four coronaviruses (HCoV-229E, -OC43, -NL63, and HKU1) are known to circulate in the population year-round and cause acute respiratory viral infection (ARVI). Usually, the above cause mild to moderate upper respiratory tract damage (1-3).

According to the results of serological and phylogenetic analyses, coronaviruses are divided into three genera: Alphacoronavirus, Betacoronavirus and Gammacoronavirus. Natural hosts of most of the currently known coronaviruses are mammals (4).

Until 2002 coronaviruses were considered to cause mild upper respiratory disorders with extremely rare lethal outcome. At the end of 2002, the coronavirus (SARS-CoV) appeared to be responsable for atypical pneumonia that caused SARS in humans. This virus belongs to the genus Betacoronavirus. A natural reservoir of SARS-CoV is bats, intermediate hosts are camels and Himalayan civets. In total, over a period (2002-2003) of the epidemic more than 8000 cases were registered in 37 countries around the world. The above included 774 fatal cases. Since 2004, no new cases of SARS-CoV-induced atypical pneumonia have been reported (5).

In 2012, the world faced a new MERS coronavirus (MERSCOV). It also belongs to the Betacoronavirus genus and appeared a causative agent of the middle East respiratory syndrome,. The main natural reservoir of MERS-CoV coronaviruses is camels. Since 2012, 2494 cases of coronavirus infection caused by the MERS-CoV have been registered, of which 858 were fatal. All cases were geographically associated with the Arabian Peninsula (82\% of cases were reported in Saudi Arabia). At the moment, MERS-CoV continues to circulate and causes new cases (6-8).

A new coronavirus was temporarily assigned 2019-nCoV by the World Health Organization (WHO - January 12, 2020). It is a single-stranded RNA-containing virus, which belongs to the Beta-CoV B lineage of the Coronaviridae family. The virus is classified as group II pathogenicity, as well as some other representatives of this family (SARS-CoV, MERS-CoV virus) (912). 
Table 1. Some data on the incidence of COVID-19 children by country as of 31.03.2020 (IPA, unpublished data)

\begin{tabular}{|c|c|}
\hline Country & Number of sick children with COVID-19 \\
\hline India & 0 (adults only) \\
\hline Turkey & 0 (adults only) \\
\hline Romania & Several cases, no deaths \\
\hline Sudan & 0 (adults only) \\
\hline Albania & Several cases, no deaths \\
\hline Ghana & 0 (adults only) \\
\hline Ivory Coast & 0 (adults only) \\
\hline Niger & 0 (adults only) \\
\hline Serbia & 2 newborns \\
\hline Malaysia & $\begin{array}{c}40 \text { children with positive tests for coronavirus, non-severe (among adults - } 1796 \text { cases and } 21 \\
\text { deaths) }\end{array}$ \\
\hline Lebanon & 1 child 2 years old, mild condition \\
\hline Uganda & 1 baby \\
\hline Sri lanka & $\begin{array}{c}7 \text { children (6 returned from Italy, } 1 \text { child from a family with a sick person), in the country } 102 \\
\text { cases in adults }\end{array}$ \\
\hline Nigeria & 1 baby 1.5 months old, arrived from USA \\
\hline Ecuador & The first lethal outcome of a 7-month-old child \\
\hline Morocco & 4-year-old boy (currently in an intensive care with a respiratory support) \\
\hline USA & $\begin{array}{l}2 \text { children in the intensive care unit (1 on CPA, the other is intubated), a father of the first child is } \\
\text { also on a mechanical ventilation }\end{array}$ \\
\hline $\begin{array}{l}\text { Lebanon and Pakistan reported a decrease in } \\
\text { the number of new cases } 2 \text { days ago }\end{array}$ & Paediatric associations in these countries believe that the peak of morbidity has passed \\
\hline
\end{tabular}

Coronavirus 2019-nCoV is presumed to be a bat - unknown origin recombinant virus. The $2019-n C o V$ genetic sequence is at least $70 \%$ similar to that of the SARS-CoV.

DFTB - dontforgetthebubbles.com scientific media project conducted a broad analysis of scientific articles related to the pediatric aspects of infection caused by SARS-CoV-2 or COVID19. From March 27, 2020 it is known that children get sick with COVID-19, as well as adults. Boys get sick a little more often. Usually the disease in children is asymptomatic or accompanied with minimal subclinical symptoms. Out of 10 sick children the symptoms include fever in 6 , sore throat in 4 and, rhinorrhea (runny nose, nasal congestion), stool disorders, vomiting in about one. Fever and other symptoms pass quickly enough. Oftenly, children have fever for 2-4 days, although in some cases it may be a week or longer (13-17).

A severe disease course is observed in 2-3 children out of 100 , designated by the WHO as a "very small proportion". The severe course may require oxygen supply, or use of artificial lung ventilation, or extracorporeal membrane oxygenation (ECMO), as well as other fairly intensive medical measures. The small number of described cases allows us for assume that risk of severe course is increased in children who suffer from certain acute or chronic diseases $(1,18)$.

Laboratory data showed that COVID-19 infection is manifested differently in children as compared to adults. The clinical picture in children is not clear and univocal. Mostly, a decrease of blood lymphocyte concentration is rare; oftenly, normal or slightly increased blood lymphocyte concentration is seen; also, non-specific inflammatory markers such as Creactive protein (CRP) and procalcitonin are oftenly slightly increased; quite often there is a slight increase in blood liver transaminase concentration (ALT and AST) $(2,19,20)$.

Since the beginning of the new coronavirus panidemic in People's Republic of China (PRC) and as of January 30, 2020 15238 people fell ill in 31 provinces of PRC. The diagnosis (Polymerase Chain Reaction) was confirmed in 9692 patients (including 1527 patients who had a severe illness, 213 who died). At the same time, $28(0.18 \%)$ cases of new infection were registered among children from birth to 17 years of age $(1,2)$.
Certainly, the epidemic in China has affected a significantly larger number of people (as of the end of March there were more than 81500 confirmed cases, 3300 deaths, 583000 and 383000 deaths in the world. respectively). However, these first data are important in terms of the ratio of cases/confirmed diagnoses/severe course/deaths and, undoubtedly, adults/children ratio $(21,22)$.

The first cases of COVID-19 infection were registered in Kazakhstan on March 13, 2020.

According to the official statistics, as of April 5, 662 cases of COVID-19 infection were registered in Kazakhstan. Out of the above, 45 were children $(6.7 \pm 0.09 \%), 46$ patients recovered $(6.9 \pm 0.01 \%)$ and 6 patients died $(0.9 \pm 0.003 \%)(23-26)$.

Another critical aspect is the appropriate diagnosis, treatment and prevention of COVID-19 infection in children. This is to exclude inappropriate diagnostics, inappropriately excessive or insufficient therapy, as well as to reduce the morbidity. The situation with the "pediatric COVID-19 epidemic" in PRC is repeated in other countries. For example, in Italy today 300 COVID-19 infected children, mostly expressed not complicated cases resulted and no deaths.

In the new borns to 9 years old group, fatal cases have not yet been registered at all. In Spain (analysis of 221 cases between the age of 10 to 19), one child died. Korea does not report deaths under the age of 30 at all. China - in the first week of February, a 14-year-old boy died in Hubei province. So far, the most extensive data have been received from China.The data from 2143 clinical cases in China contain 731 laboratoryconfirmed cases. Cases of childbirth against the background of COVID-19 are described. More than 50 women delivered while infected with COVID19. In some of the above cases COVID19 was detected in newborns, Nevertheless, in the vast majority of the above cases no vertical child mother - transmission was seen (16-19).

There are limited data that suggest that against the background of COVID-19 a risk of premature birth is slightly increased. However, in such cases, the virus was not detected in newborns, a reason and a connection with COVID-19 of premature birth is not yet clear. A role of children in the spread 
of infection is not clear, but it seems to be small. It should be borne in mind that children may be carriers of the virus without, or having minimal manifestations of infection. Therefore, it has to be kept in mind and attempted to eliminate contact between children and older people. If such contacts are unavoidable, high personal hygiene level and wearing masks are important. A possibility of fecal-oral transmission of SARS-CoV-2 has not been established. Neveretheless, at the moment it is not excluded by experts, since the virus was detected in feces of children within weeks after a disappearance of symptoms of COVID-19 (12).

A relatively small number of COVID-19 cases caused by SARS-CoV-2 infection were reported in children compared to the total number of cases in the general population. As of February 20, 2020, 2.4\% of 75,465 confirmed and suspected cases in China, occurred among people under 19 years of age. A conducted analysis in a major city in southern China suggests that among all the disease cases, the proportion of children under the age of 15 may have increased from $2 \%$ to $13 \%$ from the beginning to the end of the epidemic outbreak (14).

Of the cases reported to date in China, most children have had contact with household members with the confirmed COVID-19. In one case, a three-month-old child visited a medical facility before COVID-19 was confirmed. The above was considered the first case in a family cluster. The source of infection (health care or community) was not identified. At least one child, who mainly had gastrointestinal symptoms, sought help from several outpatient medical centers before becoming the confirmed case.

The majority of confirmed cases occurred in adults, during previous outbreaks caused by related zoonotic betacoronaviruses. The above led to severe acute respiratory syndrome (SARS) and middle East respiratory syndrome (MERS), During the SARS epidemic in 2002-2003, less than 5\% of cases were diagnosed in patients younger than 18 years of age. It is believed that most cases of SARS in patients younger than 18 years old occurred as a result of transmission from households. Although, some cases were acquired in hospital. It is also believed that most cases of MERS-CoV in children are associated with transmission of infection from households. Children may play a role in the spread of SARS-2 in the community. In one report that examined 10 infected children in China, SARS-CoV-2 ribonucleic acid (RNA) was detected in respiratory samples up to 22 days and in stool up to 30 days after the onset of symptoms. The case report of 6-month-old baby describes the detection of SARS-CoV-2 RNA in blood, stool and several nasopharyngeal swab samples. However, the only documented manifestation of the disease in the child was a constant temperature of $38.5^{\circ} \mathrm{C}\left(101.3^{\circ} \mathrm{F}\right)$. Viral culture was not sown on samples in these reports. Thus, it is unclear whether persistent or asymptomatic RNA detection is the potentially transmissible virus. It is currently unknown whether differences in the reported frequency of confirmed COVID-19 among children and adults in China are related to exposure. For instance, children are less likely to care for sick contacts, disease severity, testing or surveillance. The presented symptoms differ in case definitions for surveillance or diagnosis (13-17).

\section{Clinical Course and Complications in Children}

There are only a few articles concerning COVID-19 cases in the children's population published in the world. All of them are describing mainly patients from China. In this review patients from Kazakhstan are mentioned more often than others.

According to the latest epidemiological data, an incubation period in children is 5-7 days, insted of 1-14 days. All patients in PRC, the youngest of whom was 1.5 months old, had close contacts or were from the outbreak epicenter, including the family one. A small number of patients had fever, unproductive cough and signs of "general intoxication", while other patients had an asymptomatic clinical picture. A very small number of sick children had nasal congestion, rhinorrhea, the upper respiratory tract or nausea, vomiting, abdominal pain or discomfort, diarrhea the gastrointestinal tract symptoms. Single patients were registered with bronchitis, while there were no cases of viral pneumonia, the symptoms of lower respiratory tract damage.

In general, coronavirus infection had a light clinical picture in children, with recovery occurred within 1-2 weeks. It is noteworthy that until the end of February 2020, no newborns delivered by mothers with established COVID-19 infection had a positive result for the pathogen, which refutes the theory of SARS-CoV-2 transplacental transmission. No disease cases were registered among newborns. Later, there were publications describimg a positive test of the pathogen RNA in a newborn, 36 hours after birth (13). Since it was too delayed and the placenta and umbilical cord tissues did not contain RNA virus, the authors were not inclined to consider this fact as evidence of intrauterine infection. The same interpretation was given by the authors in their newspaper article and by the authors who described 10 other newborns with positive tests for SARS CoV-2 $(14,15)$.

Definitely, the clinical picture of a new infection in the child population should be carefully monitored with the opportunity of rapid response to new facts $(16,17)$. It is noteworthy that in previous epidemics of coronavirus infection (SARS and MERS), deaths in the child population were observed. However, the mortality rate of patients was significantly higher than in the current pandemic (approximately 30\% for MERS and 8.5\% for SARS, compared to $2.5-4.5 \%$ for COVID-19) (19-21).

\section{Epidemiological History}

- children who have traveled or lived in the epicentrum of the coronavirus infection for 14 days prior to the onset of the disease;

- children who were in contact with people from the epicentrum of infection with high fever or respiratory symptoms;

- children from families or other cluster foci of the new viral disease;

- newborns who were born to mothers infected with the new coronavirus infection.

\section{Clinical Manifestations}

1. Fever, although many pediatric patients show a subfebrile or normal temperature, unproductive cough, fatigue

2. Changes on the radiograph

3. In the onset of the disease, usual clinical blood analyses to detect leukopenia and/or lymphopenia are valuable

4. Other causative agents that may lead to similar clinical symptoms have not been identified. 


\section{Confimation of Diagnosis}

1. SARS-CoV-2 positive RT-PCR blood or respiratory tract tissue samples

2. Sequencing of respiratory tract tissue or blood samples is highly homologous for SARS-CoV-2 detection.

\section{Clinical Classification}

1. Asymptomatic infection (children with the SARS-CoV2 positive test expressing no symptoms)

2. Acute viral infection of the upper respiratory tract (children with fever, cough, sore throat, nasal congestion, headache, fatigue, myalgia, discomfort, etc., but without radiological signs of pneumonia or symptoms of sepsis)

3. Mild pneumonia (children with or without fever, respiratory symptoms like cough, etc., radiological signs of pneumonia, but no signs of severe pneumonia)

4. Severe pneumonia

a. increasing shortness of breath $>/=70$ per minute for the first year of life children, $>/=50$ per minute for a year old or older not crying children who are not at fever pitch;

b. reduced saturation $<92 \%$;

c. hypoxia: respiratory support (nasal cannula, etc.), cyanosis, intermittent breathing with episodes of apnea;

\section{Early Detection of Critical Cases (Similar to Community-} Acquired Pneumonia)

Risk groups for a development of a severe course of the disease should include children with congenital heart disease, bronchopulmonary dysplasia, respiratory tract defects, anemia/abnormal hemoglobin levels, severe malnutrition, immunodeficiency. Also, children who were treated by immunosuppressive therapy for a long time, and contactacted with COVID-19 patients, should be included in the risk groups, as well as those having one of the following symptoms:

1. Shortness of breath: $>/=60$ for children younger than 2 months old, $>50$ per minute for 2-12 months old children, $>40$ per minute for $1-5$ years old children, $>30$ per minute for children younger than 5 years old (regardless of crying or fever episode)

2. Decreased saturation $</=92 \%$

3. Fever over 3-5 days

4. Violation of consciousness (weak reaction to others, lethargy, etc.)

5. Increasing blood enzyme concentrations (hepatic, myocardial, LDH, etc.)

6. Unexplained metabolic acidosis

7. Changes detected in the chest x-ray (in the form of bilateral or multi-lobe infiltrative changes, pleural effusion or rapid increase in changes)

8. The age of a child younger than 3 months

9. Mulfunction of other organs and systems

10. Co-infection with another virus and/or bacteria

Based on limited reports from China, COVID-19 complications appear to be milder among children, as compared to adults. Severe complications, including acute respiratory distress syndrome, septic shock, etc, were reported only in one case, a 13-month-old child with confirmed COVID19. Other reports describe a mild course of the disease, including in infants. As of February 20, 2020, only one of 2114 deaths among 55924 confirmed cases of COVID-19 in China occurred among children under the age of 20 . No other details concerning the above patient have been provided $(9,19)$.

Chest X-rays of children with COVID-19 show spotty infiltrates corresponding to viral pneumonia. Chest CT scans showed nodular opacities of ground glass.

Prevailing signs and symptoms of COVID-19 reported to date among all patients are similar to other viral respiratory infections. These include fever, cough and shortness of breath. Gastrointestinal symptoms, including abdominal pain, diarrhea, nausea and vomiting, have been reported in a minority of adult patients (15).

According to the reports of nine hospitalized babies with confirmed COVID-19, in China, only half mention fever. Presently, at least one child had mainly gastrointestinal symptoms of vomiting, diarrhea and anorexia at initial presentation. To date, several reports of children with asymptomatic SARS-CoV-2 infection have been received. Data on pediatric cases of ARVI and SARS also show milder symptoms among children as compared to adults. In addition, adolescents with ARVI had more severe symptoms compared to younger children. A concurrent detection of other respiratory pathogens, including influenza, respiratory syncytial virus and Mycoplasma pneumoniae has been described in children with COVID-19. Signs and symptoms of COVID-19 in children may be similar to those of common viral respiratory infections or other childhood diseases. It is important for pediatricians to have a justified suspicion of COVID-19 infection, though to continue consiedirng and searching for other diagnoses, such as flu (14).

During the SARS outbreak in 2003-2004, patients younger than 12 years of age suffered from milder and shorter illnesses than adults, and no deaths were reported. Death was rare among children with SARS. One death from SARS was reported in a child with cystic fibrosis, respiratory samples of whom were positive for influenza A (H1N1)pdm09 and multidrugresistant Pseudomonas aeruginosa (18).

Although symptoms and course of the COVID-19 disease are milder in children than in adults, it is unknown whether the increased disease severity put children with underlying medical conditions at risk.

\section{CONCLUSIONS}

The COVID-19 epidemic has spread very quickly. In that way, at the end of January infected children in PRC accounted for a very small part of cases (about $0.18 \%$ ). The above had mild symptoms, and more often were asymptomatic carriers. However, in Kazakhstan, according to the statistics, there are 2,8 times more COVID-19 infected children. The refore, children of any age should receive special attention, since they play a huge role in spreading the disease.

\section{REFERENCES}

1. World Health Organization and United Nations Children's Fund, 'Joint Monitoring Programme', WHO and UNICEF, Geneva and New York (NY). Available at: https://washdata.org/ (Accessed: 21 March 2020). 
2. United Nations Educational, Scientific and Cultural Organization, 'COVID-19 Educational Disruption and Response', UNESCO, Paris, 2019. Available at: https://en. unesco.org/themes/education-emergencies/coronavirusschool-closures (Accessed: 21 March 2020).

3. 'Joint Monitoring Programme'.

4. World Health Organization, '2019 Novel Coronavirus (2019 nCoV): Strategic preparedness and response plan', WHO, Geneva, 3 February 2020. Available at: https://www.who. int/docs/default-source/coronaviruse/srp-04022020.pdf (Accessed: 21 March 2020).

5. The Inter-Agency Standing Committee Global Humanitarian Response Plan covers countries with humanitarian response plans, refugee response plans and joint humanitarian response plans, and represents US\$405 million of this overall UNICEF humanitarian appeal for children.

6. Bartenfeld $M$, et al. middle East respiratory syndrome Coronavirus and children. Klin Pediatrician (FILA), 2017;56(2):187-9. https://doi.org/10.1177/0009922816678 820 PMid:27872356 PMCid:PMC5288265

7. Cai J, et al. a Series of cases of children with a new coronavirus infection since 2019: clinical and epidemiological features. Clin Infect Dis, 2020.

8. Chan JF, et al. Family cluster of pneumonia associated with a new 2019 coronavirus indicating human-to-human transmission: a family cluster study. The Lancet, 2020;24:24. https://doi.org/10.1016/S0140-6736(20)301549

9. Feng $\mathrm{K}$, et al. [Analysis of $\mathrm{CT}$ features in 15 children with a new coronavirus infection in 2019]. Zhonghua Er Ke Za Zhi, 2020;58(0):E007.

10. Hon KL, et al. Clinical manifestations and outcome of severe acute respiratory syndrome in children. Lancet, 2003;361(9370):1701-3. https://doi.org/10.1016/S01406736(03)13364-8

11. Liu J, et al. Community Transmission of Severe Acute Respiratory Syndrome Coronavirus 2, Shenzhen, China, 2020. New Infectious Diseases, 2020;26(6). https://doi.org/ 10.3201/eid2606.200239

12. Memish ZA, et al. middle East respiratory syndrome coronavirus disease in children. Pediatrician Zarazi Dis J, 2014;33(9):904-6. https://doi.org/10.1097/INF.000000000 0000325 PMid:24763193

13. Pan $X$, et al. Asymptomatic cases in a family cluster with SARS-CoV-2 infection. Lancet Infect Dis, 2020. https://doi.org/10.1016/S1473-3099(20)30114-6
14. Shen K, et al. Diagnosis, treatment and prevention of new coronavirus infection in children in 2019: consensus statement of experts. World J Pediatrician, 2020.

15. Stockman LJ, et al. Severe acute respiratory syndrome in children. Pediatr Infect Dis J, 2007;26(1):68-74. https://doi.org/10.1097/01.inf.0000247136.28950.41 PMid:17195709

16. Wang D, et al. Clinical characteristics of 138 hospitalized patients with 2019 new coronavirus-infected pneumonia in Wuhan, China. JAMA, 2020. https://doi.org/10.1001/ jama.2020.1585 PMid:32031570 PMCid:PMC7042881

17. Wang M, Cao R, Zhang L, Yang X, Liu J, Xu M, et al.. Remdesivir and chloroquine effectively inhibit the newly emerging new coronavirus (2019-nCoV) in vitro . Cell Res. 2020 Feb 4. https://doi.org/10.1038/s41422-020-0282-0 PMid:32020029 PMCid:PMC7054408

18. Wei $\mathrm{M}$, et al. a New coronavirus infection in hospitalized infants under 1 year of age in China. Jama, 2020. https://doi.org/10.1001/jama.2020.2131 PMid:32058570 PMCid:PMC7042807

19. Worby $\mathrm{CJ}$, et al. on the relative role of different age groups in influenza epidemics. Epidemics, 2015;13:10-6. https://doi.org/10.1016/j.epidem.2015.04.003 PMid:26097505 PMCid:PMC4469206

20. Joint mission of the world health organization and the people's Republic of China. Report of the who-China joint mission on coronavirus disease 2019 (COVID-19). Available at: https://www.who.int/docs/default-source/coronavirus e/who-china-joint-mission-on-covid-19-final-report.pdf (Accessed: 6 March 2020).

21. Xia W, et al. Clinical and CT features in pediatric patients with COVID-19 infection: various points from adults. Children's Pulmonology. 2020;16. https://doi.org/10.1002/ ppul.24718 PMid:32134205 PMCid:PMC7168071

22. Zhang YH, et al. [2019-new coronavirus infection in a threemonth-old baby]. Zhonghua Er Ke Za Zhi, 2020;58(0):E006.

23. Kazakhstan has recorded the first two cases of coronavirus. Sputniknews.kz (March 13, 2020). Accessed March 15, 2020.

24. The two Kazakhs have identified coronavirus. Tengri News (13 March 2020). Accessed March 15, 2020.

25. The Third case of coronavirus was registered in Kazakhstan. Tengri News (March 13, 2020). Accessed March 15, 2020.

26. About the epidemiological situation of coronavirus at 23 : 20 hours. March 24, 2020 in Kazakhstan. Kazinform (March 24, 2020). Accessed March 24, 2020. 